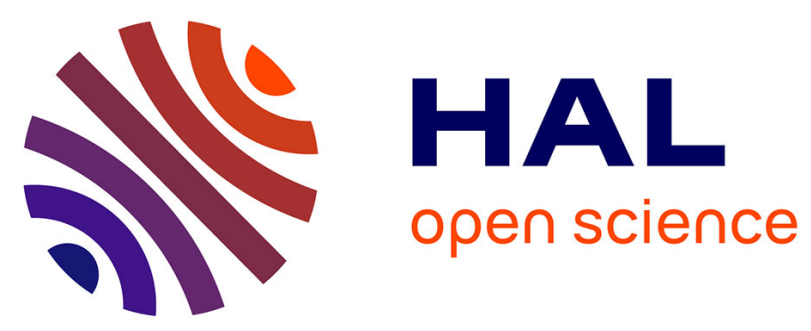

\title{
Reductive Amination/Cyclization of Methyl Levulinate with Aspartic Acid: Towards Renewable Polyesters with a Pendant Lactam Unit
}

Yann Bernhard, Sylvain Pellegrini, Till Bousquet, Audrey Favrelle, Lydie Pelinski, Frédéric Cazaux, Valérie Gaucher, Pascal Gerbaux, Philippe Zinck

\section{To cite this version:}

Yann Bernhard, Sylvain Pellegrini, Till Bousquet, Audrey Favrelle, Lydie Pelinski, et al.. Reductive Amination/Cyclization of Methyl Levulinate with Aspartic Acid: Towards Renewable Polyesters with a Pendant Lactam Unit. ChemSusChem, 2019, 12 (14), pp.3370 - $3376 . \quad 10.1002 /$ cssc.201900745 . hal-03263298

\section{HAL Id: hal-03263298 \\ https://hal.science/hal-03263298}

Submitted on 17 Jun 2021

HAL is a multi-disciplinary open access archive for the deposit and dissemination of scientific research documents, whether they are published or not. The documents may come from teaching and research institutions in France or abroad, or from public or private research centers.
L'archive ouverte pluridisciplinaire HAL, est destinée au dépôt et à la diffusion de documents scientifiques de niveau recherche, publiés ou non, émanant des établissements d'enseignement et de recherche français ou étrangers, des laboratoires publics ou privés. 


\section{CHEMISTRY \& SUSTAINABILITY

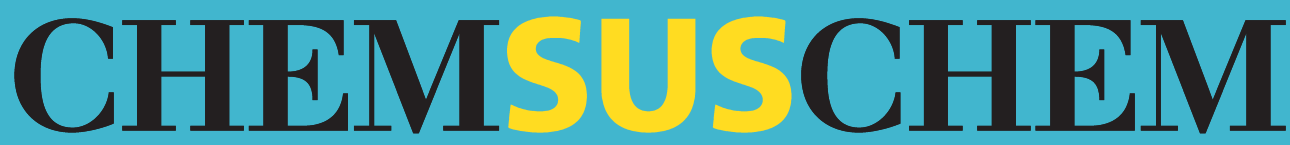

ENERGY \& MATERIALS

\section{Accepted Article}

Title: Reductive Amination/Cyclization of Methyl Levulinate with Aspartic Acid: Towards Renewable Polyesters with a Pendant Lactam Unit

Authors: Yann Bernhard, Sylvain Pellegrini, Till Bousquet, Frédéric Cazaux, Audrey Favrelle, Valérie Gaucher, Lydie Pelinski, Pascal Gerbaux, and Philippe Zinck

This manuscript has been accepted after peer review and appears as an Accepted Article online prior to editing, proofing, and formal publication of the final Version of Record (VoR). This work is currently citable by using the Digital Object Identifier (DOI) given below. The VoR will be published online in Early View as soon as possible and may be different to this Accepted Article as a result of editing. Readers should obtain the VoR from the journal website shown below when it is published to ensure accuracy of information. The authors are responsible for the content of this Accepted Article.

To be cited as: ChemSusChem 10.1002/cssc. 201900745

Link to VoR: http://dx.doi.org/10.1002/cssc.201900745 


\title{
Reductive Amination/Cyclization of Methyl Levulinate with Aspartic Acid: Towards Renewable Polyesters with a Pendant Lactam Unit
}

\author{
Yann Bernhard, ${ }^{a}$ Sylvain Pellegrini, ${ }^{a}$ Till Bousquet, ${ }^{a}$ Audrey Favrelle, ${ }^{a}$ Lydie Pelinski, ${ }^{a}$ Frédéric \\ Cazaux, ${ }^{b}$ Valérie Gaucher, ${ }^{b}$ Pascal Gerbaux ${ }^{c}$ and Philippe Zinck*a
}

\begin{abstract}
Environmental regulation and fossil resources depletion boost the search for new polymeric materials produced from biomass. Here, we report the synthesis of a novel diester bearing a pendant lactam unit from methyl levulinate and aspartic acid. The palladiumcatalyzed reductive amination/cyclization sequence was carefully optimized to afford the diacid with high yield (>95\%). In a second step, the compound was esterified to give the corresponding diester. The latter monomer was copolymerized with $\alpha-\omega$ linear diols yielding polyesters with molecular weights up to $20.5 \mathrm{~kg} \cdot \mathrm{mol}^{-1}$.
\end{abstract}

\section{Introduction}

As a consequence of fossil resources depletion as well as environmental issues, the production of chemicals, fuels and polymeric materials from biomass has attracted growing interest. ${ }^{1}$ In this context, lignocellulosic biomass seems promising as a C5/C6 carbohydrate feedstock due to its abundance and its great economic and environmental potential. ${ }^{2}$ The transformation of such polysaccharides gives access to a large panel of green chemical building blocks like lactic acid, 5-HydroxyMethylFurfural (5-HMF), succinic acid, glutaric acid and several others. ${ }^{3}$ Among them, Levulinic Acid (LevOH) and Aspartic Acid (AspOH) have been defined as two of the top twelve chemical building blocks by the US Department of energy in 2004, and still remain promising. ${ }^{1 \mathrm{~b}}$

$\mathrm{LevOH}$ is a cost competitive renewable feedstock, as it is easily mass-produced on multi-ton scale. It generally involves the rehydration of 5-HMF which is obtained from acid catalyzed transformation of abundant cellulose based sugars. ${ }^{4}$ The worldwide consumption is nowadays around 2600 tons per year,

[a] Dr. Y. Bernhard, Dr, S Pellegrini, Dr. T. Bousquet, Dr. A. Favrelle, Prof. L. Pelinski, Prof. P. Zinck Univ. Lille, CNRS

Centrale Lille, ENSCL, Univ. Artois, UMR 8181-UCCS-Unité de Catalyse et Chimie du Solide

F-59000 Lille (France)

E-mail: philippe.zinck@univ-lille1.fr

[b] Dr. F. Cazaux, Pr. V. Gaucher

Univ. Lille, CNRS

INRA, ENSCL, UMR 8207 - UMET - Unité Matériaux et

Transformations

F-59000 Lille (France)

[c] Pr.P. Gerbaux

University of Mons-UMONS

Organic Synthesis \& Mass Spectrometry Laboratory

23 Place du Parc, B-7000 Mons, Belgium

Supporting information for this article is given via a link at the end of the document. but it may increase steadily due to the development of the biofine process. ${ }^{5}$ Alkyl levulinates, as Methyl Levulinate (LevOMe), are easily synthesized by esterification of $\mathrm{LevOH},{ }^{6}$ but can also be directly obtained from the cellulosic biomass, ${ }^{7}$ and from microalgae. ${ }^{8}$ LevOH and LevOMe are valuable platform chemicals that are converted into value-added products finding places in a broad range of applications like fuel, additives, pharmaceutical intermediates, solvents, plasticizers and polymers. 5,9 As specific examples of its use as a polymer precursor, $\mathrm{LevOH}$ can be converted to monomers like $\mathrm{Y}^{-}$ valerolactone, $\quad \beta$-methyl- $\alpha$-methylene- $y$-butyrolactone, ${ }^{10} \quad 1,4$ pentanediol, ${ }^{9 b}$ succinic acid, ${ }^{11} \alpha$-angelicalactone, ${ }^{12}$ or 5 hydroxylevulinic acid. ${ }^{13}$ It has also been converted to polyesters or polyurethanes via the formation of ketals. ${ }^{14}$ Another interest lies in diphenolic acid, which is considered as a renewable substitute to bisphenol-A for polycarbonates. ${ }^{15}$ For those purposes, selective and efficient homogeneous or heterogeneous catalytic transformations of LevOH are recognized as a key technology. ${ }^{2 e, 16}$ From the different pathways, the reductive amination with primary amines and the subsequent cyclization is one of the most attractive methods. ${ }^{9 b}$ Indeed, it gives access to value-added $\mathrm{N}$-substituted-5-methyl-pyrrolidone which are promising biosourced solvents, alternatives to the widely used toxic and carcinogenic $\mathrm{N}$-methyl-pyrrolidone (NMP). ${ }^{17}$ The synthesis involves the hydrogenation of a Schiff based intermediate to afford a secondary amine, which is subsequently converted to a lactam ring via an intramolecular cyclization. Such a sequence has been reported with $\mathrm{H}_{2}$, formic acid or hydrosilanes as the hydrogen source, and with various homogeneous catalysts based on $\mathrm{Al},{ }^{18} \mathrm{Ru},{ }^{19} \quad \mathrm{Ir}^{20}{ }^{20} \ln .{ }^{21}$ Heterogeneous catalysts - generally supported on metal oxides like $\mathrm{Au},{ }^{22} \mathrm{Ni},{ }^{23} \mathrm{Pd},{ }^{24} \mathrm{Pt},{ }^{25} \mathrm{Ru},{ }^{26} \mathrm{Ir},{ }^{26 a, 27}$ were also assessed, as well as reaction without catalyst. ${ }^{28}$ Similarly, the access to $N$ substituted-pyrrolidones by a palladium catalyzed reductive amination from glutamic acid and aldehydes or ketones, followed by a decarboxylation, has been described. ${ }^{29}$

AspOH is an amino-acid found in plants, bacteria and sugars. Nevertheless, the most common route to biobased $\mathrm{AspOH}$ is via enzymatic catalysis, reacting ammonia with fumaric acid in the presence of a lyase enzyme. ${ }^{2 \mathrm{c}, 3 \mathrm{~b}}$ Its direct production from sugars is more desirable, but not possible with the current technology. An interesting potential feedstock for L-aspartic acid is the cyanophycin polypeptide - a poly(L-aspartic acid) backbone with branched L-arginine moieties - that has been produced on pilotscale from protamylase, an amino acid-rich waste from potato starch. ${ }^{1 \mathrm{c}, 30} \mathrm{AspOH}$ has been used as a building block to prepare many valuable compounds, including fumaric acid, maleic acid, $\beta$ alanine, aspartic anhydride and amino-y-butyrolactone. ${ }^{2 c, 31}$ Moreover, water-soluble biodegradable specialty polymers, 
polyaspartic acid and polyaspartates, offer new potential markets as substitutes for polyacrylic acid and polycarboxylates. ${ }^{3 b, 32}$

Polyesters are used in many fields and have great potential as ecofriendly polymers as i) the ester functionality is an obvious point of degradability via hydrolysis and ii) they are very accessible from bio-based building blocks. ${ }^{33}$ Miller and coworkers have recently reported the synthesis of a hydroxyacid bearing a lactam group in the chain, leading to a poly(ester-co-amide) polymer after polycondensation (Scheme 1). ${ }^{34}$ The lactam group has also been incorporated from itaconic acid and diamines by Kaneko and coworkers, ${ }^{35}$ or via the multicomponent 4CR-Ugi reaction from LevOH by Becer and coworkers. ${ }^{36}$

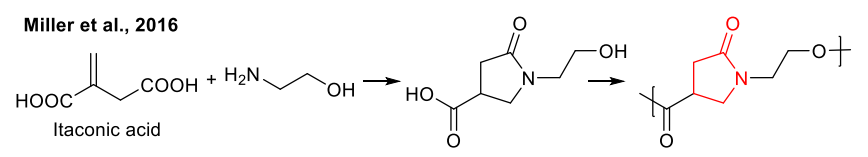

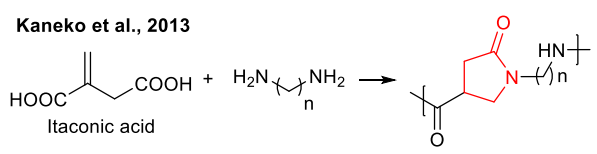

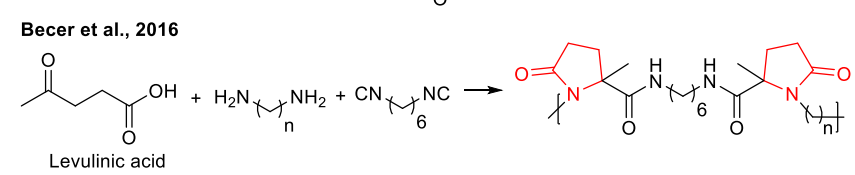

Scheme 1. Polyamides and polyesters containing lactam ring starting from biobased itaconic acid and levulinic acid.

From these inspiring studies and following our previous researches in the reductive amination of levulinic acid with secondary amine substrates and the subsequent synthesis of renewable poly(ester-co-amine) polymers, ${ }^{37}$ we report herein the synthesis of polyesters bearing a pendant lactam group (PAMPS, Scheme 2) by the polycondensation of biobased $\alpha-\omega$ linear diols with a diester derived from levulinic acid. This monomer was synthesized by a green sequential catalyzed reductive amination/cyclization strategy starting from the key biobased building blocks LevOMe and AspOH. (DMMPS, Scheme 2).

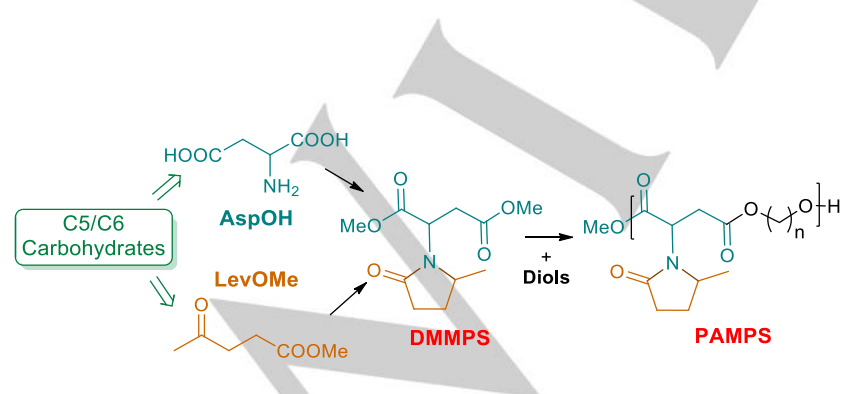

Scheme 2. Synthesis of the monomer DiMethyl 2-(2-Methyl-5-oxoPyrrolidin-1yl) Succinate (DMMPS) from biobased Methyl Levulinate (LevOMe) and Aspartic Acid (AspOH), and Poly[Alkylydene 2-(2-Methyl-5-oxoPyrrolidin-1-yl) Succinate] (PAMPS) polymers.

\section{Results and Discussion}

\section{Monomer synthesis}

The dicarboxylic acid bearing a pendant lactam group (MPSA, Table 1) was synthesized by a sequential reductive amination/cyclization reaction starting from racemic aspartic acid (AspOH) and methyl levulinate (LevOMe). Our first attempts were realized on aspartic acid dimethyl ester in the presence of reducing agent such as borohydride reagents (Table S1, see SI). However, low yields were obtained because of the absence of cyclization after reductive amination reaction. We decided to investigate a greener catalytic approach to improve the yield and the selectivity toward the lactam product.

Table 1. Optimization of the reductive amination of methyl levulinate (LevOMe) with aspartic acid $(\mathrm{AspOH})^{\mathrm{a}}$

\begin{tabular}{|c|c|c|c|c|c|c|}
\hline & AspoH & LevO & & $\begin{array}{c}\mathrm{H}_{2}(\mathrm{P}) \\
(10 \mathrm{wt} \% \text { on }\end{array}$ & & \\
\hline Entry & Solvent & $\begin{array}{l}\text { LevOMe } \\
\text { (Equiv.) }\end{array}$ & $\begin{array}{c}\mathrm{T} \\
\left({ }^{\circ} \mathrm{C}\right) \\
\end{array}$ & $\begin{array}{l}\text { Catalyst } \\
(\mathrm{mol} \%)\end{array}$ & $\begin{array}{l}\mathrm{P}_{\mathrm{H} 2} \\
\text { (bar) }\end{array}$ & $\begin{array}{l}\text { Yield } \\
(\%)^{d}\end{array}$ \\
\hline 1 & $\mathrm{H}_{2} \mathrm{O}$ & 5 & 80 & 2.5 & 50 & 0 \\
\hline 2 & $\mathrm{EtOH}$ & 5 & 80 & 2.5 & 50 & 42 \\
\hline 3 & $\mathrm{EtOH}$ & 10 & 80 & 2.5 & 50 & 43 \\
\hline $4^{b}$ & $\mathrm{EtOH}$ & 10 & 80 & 2.5 & 50 & 48 \\
\hline 5 & Neat & 5 & 130 & 2.5 & 50 & 36 \\
\hline 6 & $\mathrm{EtOH} / \mathrm{H}_{2} \mathrm{O}$ & 5 & 80 & 2.5 & 50 & 78 \\
\hline 7 & $\mathrm{MeOH}$ & 5 & 70 & 2.5 & 50 & 95 \\
\hline 8 & $\mathrm{MeOH}$ & 5 & 70 & 1.25 & 50 & 51 \\
\hline 9 & $\mathrm{MeOH}$ & 5 & 70 & 2.5 & 20 & 76 \\
\hline $10^{c}$ & $\mathrm{MeOH}$ & 5 & 70 & 2.5 & 50 & 65 \\
\hline 11 & $\mathrm{MeOH}$ & 3 & 70 & 2.5 & 50 & 93 \\
\hline 12 & $\mathrm{MeOH}$ & 2 & 70 & 2.5 & 50 & 54 \\
\hline
\end{tabular}

[a] Reaction in a $40 \mathrm{~mL}$ batch autoclave, on $0.5 \mathrm{~g}$ AspOH scale, with $10 \mathrm{~mL}$ of solvent. [b] With $5 \mathrm{~mol} \%$ of $\mathrm{AcOH}$. [c] $\ln 5 \mathrm{~mL}$ of solvent. [d] Isolated yield.

In a typical procedure, the reaction was carried out in the presence of palladium charcoal as catalyst under pressure of $\mathrm{H}_{2}$. The use of LevOMe instead of Levulinic Acid presents the advantage to be easily separated from MPSA by extraction at the end of the reaction. The results of the reaction optimization were summarized in Table 1. Unfortunately, the reaction conducted in water was inefficient as the LevOMe is insoluble in this media (entry 1 ). However, it was quite efficient in ethanol even if the yield was moderate due to the limited solubility of $\mathrm{AspOH}$ (entry 2). The use of a large excess of LevOMe or the addition of acetic acid to catalyze the cyclization did not allow increasing the yield (entries 3 and 4). When the reaction was performed without solvent at higher temperatures, the yield dropped to $36 \%$ (entry 5). The addition of water efficiently improved the yield to $78 \%$ (entry 6 ). MPSA was obtained in isolated yield of $95 \%$ 
when the reaction was realized in methanol (entry 7). We next tried to decrease several parameters like catalyst loading to $1.25 \%$ (entry 8 ), hydrogen pressure to 20 bar (entry 9 ) or the dilution of the reaction (entry 10), but the yield was lower in each case. At least three equivalents of LevOMe were necessary to obtain a yield $>90 \%$ (entry 7 vs. 11 and 12).

In our quest to a green synthetic process, we also considered the possibility to reuse the palladium heterogeneous catalyst (Table 2, entries 1-3). It can be recovered by filtration after the reaction, dried, and re-engaged to afford MPSA with similar yields. The scale-up of the reaction was also realized. We first carried out the MPSA synthesis starting from $2.0 \mathrm{~g}$ of AspOH. MPSA was obtained in similar yield (entry 4). However, a decrease of the reaction efficiency was observed when the reaction was realized in the presence of $7.5 \mathrm{~g}$ of AspOH certainly due to the moderate AspOH solubility in methanol (entry 5).

Table 2. Synthesis of MPSA i) reusing the palladium on charcoal, ii) performing the scale-up of the reaction. ${ }^{a}$

\begin{tabular}{cccc}
\hline Entry & Pd reusing trial & AspOH scale $(\mathrm{g})$ & MPSA yield $(\%)^{\mathrm{b}}$ \\
\hline 1 & 0 & 0.5 & 95 \\
2 & 1 & 0.5 & 93 \\
3 & 2 & 0.5 & 92 \\
$4^{\mathrm{c}}$ & 0 & 2.0 & 90 \\
$5^{\mathrm{d}}$ & 0 & 7.5 & 74 \\
\hline
\end{tabular}

[a] Typical procedure: in a $40 \mathrm{~mL}$ batch autoclave, with 5 eq. of LevOMe, with $10 \mathrm{~mL}$ of solvent, 50 bar of $\mathrm{H}_{2}$, at $80^{\circ} \mathrm{C}$ for 24 hours. [b] Isolated yield. [c] In a $100 \mathrm{~mL}$ autoclave, with $40 \mathrm{~mL}$ of $\mathrm{MeOH}$. [d] In a $300 \mathrm{~mL}$ autoclave, with $150 \mathrm{~mL}$ of $\mathrm{MeOH}$ and mechanical stirring.

The product MPSA was next converted to the dimethyl ester DMMPS for two reasons. First, it is so highly hygroscopic, that makes it difficult to handle. Then, DMMPS can advantageously be purified by distillation under reduced pressure (purity $>99 \%$ ), (Gas Chromatography, Figure S5). The reaction was conducted in methanol with a catalytic amount of sulfuric acid (Scheme 3). Thereby, DMMPS was synthesized in two steps directly from the biobased building blocks, and isolated in $86 \%$ overall yield with a straightforward and economical purification method. The synthesized product was fully characterized by ${ }^{1} \mathrm{H}$ and ${ }^{13} \mathrm{C}$ NMR spectroscopy and high-resolution mass spectrometry (see $\mathrm{SI}$ ). The ${ }^{1} \mathrm{H}$ NMR spectrum (Figure 1, top) is relatively complex due to the presence of two asymmetric centers. It is noticeable that the synthesis was realized starting from racemic DL-Aspartic acid. Thus, the DMMPS was isolated as a mixture of diastereomers in a 64/34 ratio.

Then, we also considered the possibility to conduct this synthetic sequence starting from other tri-functional aminoacids as serine (SerOH), and glutamic acid (GluOH) to afford two new lactam-containing monomers, the hydroxyester MHMPP (Scheme 4) and the diester DMMPG (Scheme 5).

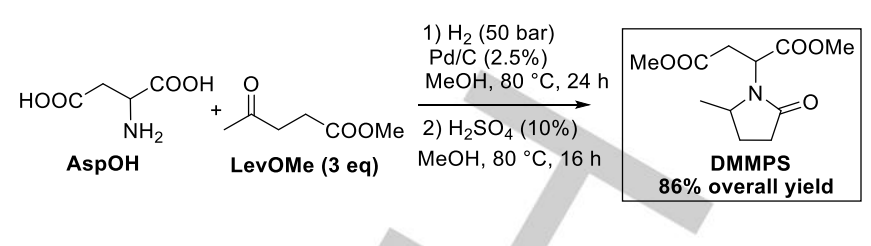

Scheme 3. Summary of the synthesis of the monomer DMMPS

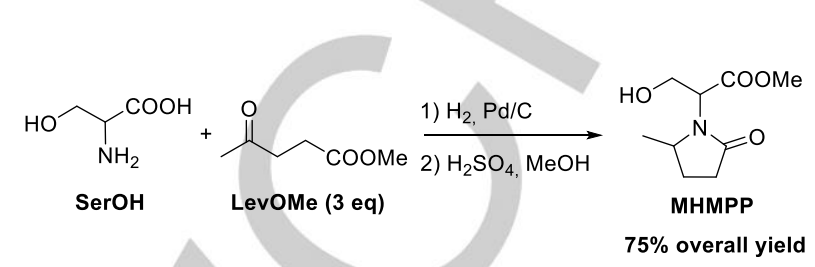

Scheme 4. Synthesis of the monomer Methyl 3-Hydroxy-2-(2-Methyl-5oxoPyrrolidin-1-yl)Propanoate (MHMPP) from serine (SerOH).

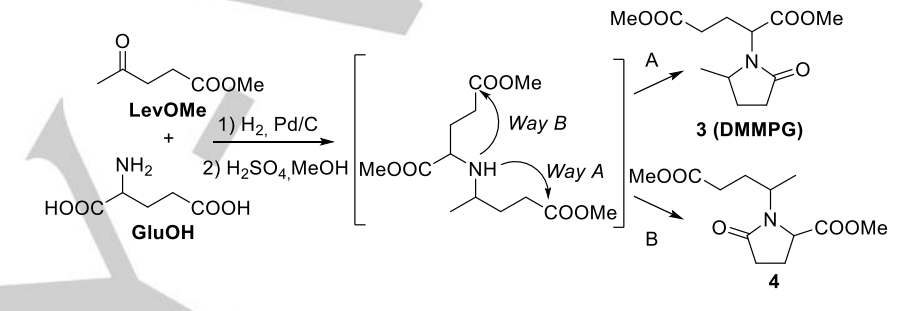

Scheme 5. Synthesis of compounds 3 (DiMethyl 2-(2-Methyl-5-oxoPyrrolidin-1yl) Glutarate -DMMPG) and 4 starting from glutamic acid (GluOH).

The synthesis from SerOH was efficiently conducted with the same experimental conditions as previously described (Scheme 4). The MHMPP was obtained in $75 \%$ overall yield. Unfortunately, the sequence from GluOH afforded a mixture of two isomers 3 and 4 , arising from the two possible ways of cyclization. That was highlighted by the ${ }^{1} \mathrm{H}$ NMR of the reaction mixture (Figure S10). As it was not possible to separate these two compounds, this precursor was not further investigated.

\section{Polymer Synthesis.}

Thereafter, the polycondensation of the renewable diester DMMPS with 1,6-hexanediol was investigated. A classical two steps procedure was applied, starting from an oligomerization step under argon for 5 hours and followed by an 8 hour period under dynamic vacuum to remove the methanol by-product. The temperature was initially set at 180 ${ }^{\circ} \mathrm{C}$ to avoid the degradation of the monomer. A slight excess of diol was used as it is generally described to lead to higher molecular weight. ${ }^{34,38}$ Table 3 shows the yield, the numberaverage molecular weight $\left(M_{n}\right)$ and the dispersity $(\Xi)$ measured by SEC analysis of the crude polymer, from a survey of six catalysts $(0.1 \mathrm{~mol} \%)$. The use of the Brönsted base (potassium carbonate, $\mathrm{K}_{2} \mathrm{CO}_{3}$ ), the Brönsted acid ( $p$ toluene sulfonic acid, $\mathrm{TsOH}$ ) and the Lewis acid 
(antimony(III) oxide, $\mathrm{Sb}_{2} \mathrm{O}_{3}$ ) only allowed oligomer production (entries 1-3). Titanium isopropoxyde led to a number-average molecular weight of $18.4 \mathrm{~kg} \cdot \mathrm{mol}^{-1}$ (entry 4). The highest $\mathrm{M}_{\mathrm{n}}$ of $20.5 \mathrm{~kg} \cdot \mathrm{mol}^{-1}$ was obtained using Tin(II) octoate, giving a PHMPS with $80 \%$ yield and a dispersity $Ð$ of 1.7 (entry 5). Afterwards, other polyesters were synthesized using this latter catalyst, which is FDAapproved.

Table 3. Catalyst screening for the polymerization of DMMPS with 1,6hexanediol as co-catalyst-

\begin{tabular}{|c|c|c|c|}
\hline$\overbrace{\text { DMMPS }}^{N}$ & $\begin{array}{l}\mathrm{HO}-\left(\mathrm{CH}_{2}\right)_{6}-\mathrm{C} \\
\quad 1.06 \mathrm{eq}\end{array}$ & $\begin{array}{l}\% \text { Catalyst } \\
\stackrel{{ }^{\circ} \mathrm{C}, \mathrm{Ar}, 5 \mathrm{~h}}{\longrightarrow} \\
\mathrm{C}, \text { vac., } 8 \mathrm{~h}\end{array}$ & $\begin{array}{l}\mathrm{H}_{2}+\mathrm{C} \\
6\end{array}$ \\
\hline Entry & Catalyst & Yield (\%) & $\mathrm{M}_{\mathrm{n}}\left(\mathrm{kg} \cdot \mathrm{mol}^{-1}\right)^{\mathrm{a}}(\bigoplus)$ \\
\hline 1 & $\mathrm{~K}_{2} \mathrm{CO}_{3}$ & 42 & $1.7(1.2)$ \\
\hline 2 & $\mathrm{TsOH}$ & 73 & $2.1(1.2)$ \\
\hline 3 & $\mathrm{Sb}_{2} \mathrm{O}_{3}$ & 38 & $1.9(1.2)$ \\
\hline 4 & $\mathrm{Ti}(\mathrm{O} / \mathrm{Pr})_{4}$ & 91 & $18.4(2.1)$ \\
\hline 5 & $\mathrm{Sn}(\mathrm{Oct})_{2}$ & 80 & $20.5(1.7)$ \\
\hline
\end{tabular}

[a] GPC in THF at $40^{\circ} \mathrm{C}$. vs. polystyrene standards. Value not corrected.

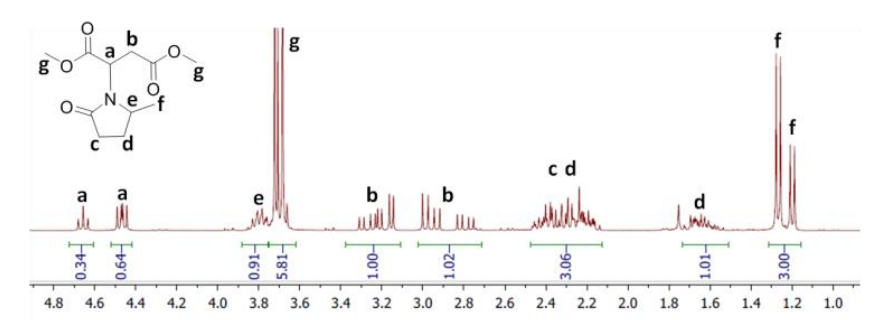

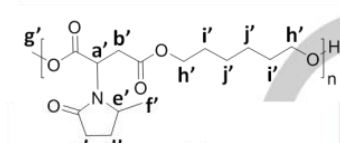

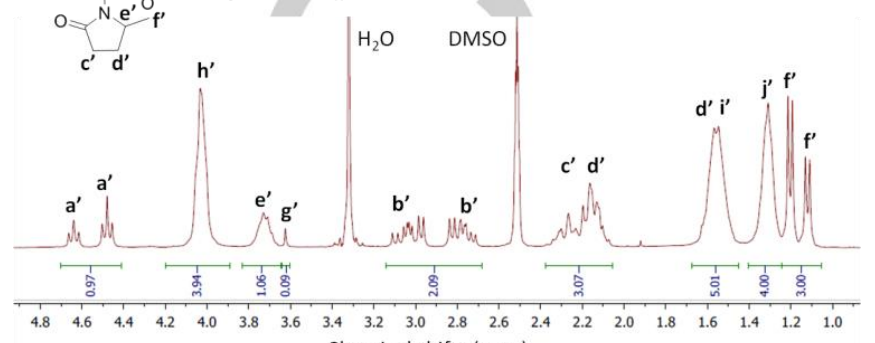

Chemical shifts (ppm)

Figure 1. ${ }^{1} \mathrm{H}$ NMR Spectra of the monomer DMMPS (top, $\mathrm{CDCl}_{3}, 300 \mathrm{MHz}, 300 \mathrm{~K}$ ) and the polymer PHMPS (bottom, DMSO- $\mathrm{d}_{6}, 300 \mathrm{MHz}, 300 \mathrm{~K}$ ) synthesized with $\mathrm{Sn}(\mathrm{Oct})_{2}$ as the catalyst.
The polymer was further characterized by proton and carbon NMR spectroscopy. The ${ }^{1} \mathrm{H}$ NMR spectrum of PHMPS is presented Figure 1 (bottom) compared with that of the monomer DMMPS (top). On the polymer spectrum, the polymerization is first evidenced by the almost disappearance of the signal of the protons of the methyl ester $g$ and the presence of new signals attributed to the methylene of the diols unit, i.e. $h^{\prime}$ at $4.05 \mathrm{ppm}, i^{\prime}$ at $1.5 \mathrm{ppm}$ and $j$ ' at $1.3 \mathrm{ppm}$. The methyl ester $(g)$ is also noticeable as it appears as a low intensity singlet at $3.62 \mathrm{ppm}$. The polymer was also characterized by FT-IR spectroscopy (Figure S16). The absorption bands at $1734 \mathrm{~cm}^{-1}$ and $1685 \mathrm{~cm}^{-1}$ correspond to the carbonyl groups of the ester and the amide, respectively.

Then, the homopolymerization of the MHMPP obtained from the SerOH was also investigated, using the previously established polycondensation conditions (Scheme 6). The whole mixture was here evaporated from the bulk with the methanol by-product and recovered in the external trap. The ${ }^{1} \mathrm{H},{ }^{13} \mathrm{C}$ NMR and GC-MS analyzes of this distillate (Figure S11-13) point to the monomer instability at this temperature. A dehydration reaction led to an $\alpha, \beta$-unsaturated derivative. Therefore, access to polyesters from this monomer was not further considered.
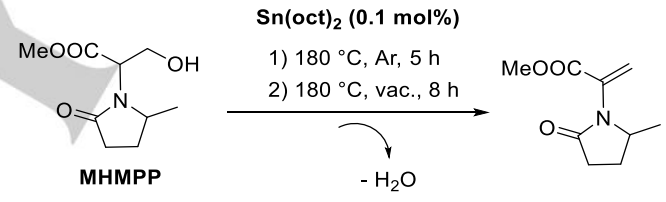

Scheme 6. Trial of polymer synthesis from MHMPP.

The polycondensation of MPSA was next realized using diols with different chain-lengths to tune the structure of the resulting polymer. C2 to C5 $\alpha-\omega$ linear diols were assessed under the experimental conditions optimized with hexanediol. The results are presented in Table 4. Starting from 1,5-pentanediol and 1,4-butanediol, the polymers PPeMPS and PBMPS were obtained with $92 \%$ and $83 \%$ yields, and number-average molecular weights of 14.3 and $9.8 \mathrm{~kg} \cdot \mathrm{mol}^{-1}$, respectively (entries 2 and 3 ). The polymerization conducted with 1,3-propanediol and ethyleneglycol led to lower molecular weight polymers (entry $4-5)$, even after an increase of the temperature of the second step to $200^{\circ} \mathrm{C}$ for the latter.

The thermal properties of these polyesters bearing a pendant lactam group were assessed by differential scanning calorimetry (DSC) and thermogravimetric analysis (TGA). The glass transition temperature increases as the number of carbons of the diol decreases, from ca. $5^{\circ} \mathrm{C}$ (C6) to $44^{\circ} \mathrm{C}$ for the $\mathrm{C} 2$. The absence of melting temperatures on the thermograms highlights fully amorphous polymers. In comparison, the glass transition temperature of the main poly(alkylene succinate), including polybutylene succinate 
Table 4. Scope of the diol comonomer in the polymerization of DMMPS with $\mathrm{Sn}(\mathrm{oct})_{2}$ as catalyst and thermal properties of the PAMPS. ${ }^{a}$

\begin{tabular}{|c|c|c|c|c|c|c|c|c|c|}
\hline Entry & Polymer name & Polymer structure & $\begin{array}{c}\text { Monomer ratio } \\
\text { (diester:diol) }\end{array}$ & $\begin{array}{c}\text { Yield } \\
(\%)\end{array}$ & $\mathrm{M}_{\mathrm{n}}\left(\mathrm{kg} \cdot \mathrm{mol}^{-1}\right)^{\mathrm{d}}$ & $\bigoplus^{d}$ & $T_{g}\left({ }^{\circ} \mathrm{C}\right)^{e}$ & $T_{d 50}\left({ }^{\circ} \mathrm{C}\right)^{f}$ & $\begin{array}{c}T_{g}\left({ }^{\circ} \mathrm{C}\right)^{[\text {Ref }]} \\
\text { linear }{ }^{g} \\
\end{array}$ \\
\hline 1 & PHMPS & & 1.06 & 79 & 20.5 & & & 377 & $-49^{39}$ \\
\hline 2 & PPeMPS & & 1.06 & 92 & 14.3 & 1.9 & & 360 & $-44^{40}$ \\
\hline 3 & PBMPS & & 1.06 & 83 & 9.8 & 2.0 & 21 & 335 & $-44^{41}$ \\
\hline 4 & PPMPS & & 1.06 & 81 & 4.9 & 1.7 & 24 & 337 & $-41^{42}$ \\
\hline $5^{b}$ & PEMPS & & 1.16 & 94 & 4.8 & 1.6 & 45 & 328 & $-11^{41}$ \\
\hline
\end{tabular}

a Typical procedure: 0.1 mol\% Sn(oct) $2,180^{\circ} \mathrm{C}$, under i) nitrogen for 5 hours, then ii) dynamic vacuum for 8 hours. [b] Step ii) at $200{ }^{\circ} \mathrm{C}$, with $0.2 \% \mathrm{Sn}(\mathrm{Oct}) 2$. [C] Name of the different Poly[Alkylydene 2-(2-Methyl-5-oxoPyrrolidin-1-yl) Succinate] were the alkylydene can be: Hexylene (PHMPS), Pentylene (PPeMPS), Butylene (PBMPS), Propylene (PPMPS) and Ethylene (PEMPS). [d] GPC in THF at $40^{\circ} \mathrm{C}$ vs. polystyrene standards. Value not corrected. [e] Determined by DSC on the second heating curve. [f] TGA temperature at which $50 \%$ mass loss was observed under nitrogen, with a heating rate of $10{ }^{\circ} \mathrm{C}$.min-1. [g] Value from literature, with corresponding reference, of $\mathrm{Tg}$ of similar polymers without the lactam ring, i.e. poly(alkylydene succinate), where the alkylydene is hexylene, pentylene, butylene, propylene and ethylene.

(PBS), are given in the Table 4 . The lactam ring brings a substantial rigidity, leading to an impressive increase of the $\mathrm{Tg}$, from ca. $60^{\circ} \mathrm{C}$ when compared to the non-functionalized poly(alkylene succinate), while also hampering the crystallization of the polymer. Table 4 also presents the $T_{d 50}$ values, the temperature at which $50 \%$ of the mass loss occurs according to TGA analysis under nitrogen, with a ramp of $10^{\circ} \mathrm{C} \cdot \mathrm{min}^{-1}$. Contrary to the $\mathrm{Tg}, \mathrm{T}_{\mathrm{d} 50}$ value decreases as the length of the diol decreases. Such polymers could be of interest as components for biobased paintings and coatings, the pendant lactam being expected to provide good adhesion to a substrate and possibly hardness improvement.

\section{Conclusions}

In an unprecedented manner, two of the top chemical building blocks from biomass, methyl levulinate and aspartic acid were reacted together to afford a novel monomer with a pendant lactam unit. $A$ one-pot palladium-catalyzed reductive amination/cyclization sequence was selected as a green synthetic pathway to construct the lactam ring. The choice of the solvent and the number of equivalents of methyl levulinate are the key parameters of the reaction to selectively obtain the cyclic monomer with high yield. After esterification, the DMMPS diester was efficiently purified by distillation to reach a high purity. This two-step catalytic process is scalable, and the palladium catalyst can be reused. Starting from this diester, biobased polyesters PAMPS were synthesized via copolymerisation with various diols. From a survey of catalysts, tin octanoate was identified as the most performant to promote the two stages melt polycondensation at $180^{\circ} \mathrm{C}$ leading to a PHMPS with high yield and $M_{n}$ up to $20.5 \mathrm{~kg} \cdot \mathrm{mol}^{-1}$. From the library of these new functionalized polyesters, the thermal properties scale proportionally with the lactam methylene ratio. The glass transition temperature increases with the rigid lactam density, up to $44{ }^{\circ} \mathrm{C}$ with ethyleneglycol, when the $50 \%$ decomposition temperature increases with the stable methylene unit density, up to $354^{\circ} \mathrm{C}$. Future work will aim to study the application of those new materials, notably as coatings components.

\section{Experimental Section}

General. Chemicals used in this study have been purchased from various providers and were used without additional purification. Monomers were analysed by ${ }^{1} \mathrm{H}$ and ${ }^{13} \mathrm{C}-\mathrm{NMR}$ spectroscopy, GC chromatography, and high-resolution mass spectrometry. ${ }^{1} \mathrm{H}$ NMR and ${ }^{13} \mathrm{C}$ NMR spectra were recorded on a Bruker $\mathrm{AC} 300$ spectrometer at room temperature with $\mathrm{CDCl}_{3}$ or DMSO-D6 as the solvent. High resolution mass spectra (HRMS) were measured on a Waters Synapt G2-Si (mode ESI(+)) at the University of Mons, Belgium. Polymers were analysed by ${ }^{1} \mathrm{H}$ and ${ }^{13} \mathrm{C}-\mathrm{NMR}$ 
WILEY-VCH

spectroscopy, Size Exclusion Chromatography (SEC), Differential Scanning Microscopy (DSC) and ThermoGravimetric Analysis (TGA). The number-average molecular weight $\left(M_{n}\right)$ and the dispersity $(\Theta)$ were determined by Size Exclusion Chromatography (SEC) in tetrahydrofuran at $40{ }^{\circ} \mathrm{C}$ with a flow rate of $1 \mathrm{~mL} / \mathrm{min}$. The $\mathrm{Mn}_{\mathrm{n}}$ and the $\boxminus$ were derived from the Refractive Index (RI) signal with a calibration curve based on PolyStyrene (PS) standards from Polymer Standards Service. Thermal characterization of copolymers was performed with a DSC7 Perkin-Elmer instrument calibrated according to standard procedures using a high purity Indium sample. For the analyses, samples $(10 \mathrm{mg})$ were placed into aluminium pans and heated from $-70^{\circ} \mathrm{C}$ to $180^{\circ} \mathrm{C}$ at a rate of $10^{\circ} \mathrm{C} / \mathrm{min}$.

Monomer synthesis. Hydrogenation reactions were performed in a $40 \mathrm{~mL}$ or a $100 \mathrm{~mL}$ high-pressure magnetically stirred Maximator ${ }^{\circledR}$ stainless-steel autoclave $(0.5-2 \mathrm{~g}$ scale) or in a $300 \mathrm{~mL}$ mechanically stirred Parr stainless-steel autoclave $(7.5 \mathrm{~g}$ scale).

2-(2-Methyl-5-oxopyrrolidin-1-yl)succinic acid (MPSA). The autoclave was charged with AspOH (0.5 g, $3.76 \mathrm{mmol})$, LevOMe (2.3 mL, 18.80 $\mathrm{mmol})$, Pd $10 \mathrm{wt} \%$ on charcoal $(100 \mathrm{mg}, 0.09 \mathrm{mmol}$ ) and methanol. The autoclave was sealed, purged three times with hydrogen, and then pressured at 50 bars of $\mathrm{H}_{2}$. The reaction mixture was stirred for $24 \mathrm{~h}$ at $70{ }^{\circ} \mathrm{C}$. After cooling down to room temperature and depressurization, the reaction mixture was filtered on a short pad of Celite $\AA$ to remove catalyst, then concentrated under reduced pressure. The residue was taken in $30 \mathrm{~mL}$ of water and extracted three times with organic solvent (DCM or AcOEt) $(3 \times 20 \mathrm{~mL})$ to remove the excess of LevOMe. The aqueous layer was concentrated under reduced pressure. The resultant viscous oil was dried under reduced pressure for several hours to afford the pure diacid MPSA as a highly hygroscopic white powder $(0.79 \mathrm{~g}$ starting from 0.5 of AspOH, 95\% yield).

3-Hydroxy-2-(2-methyl-5-oxopyrrolidin-1-yl)propanoic acid (HMPPA). The compound was prepared via analogous procedure. Dimethyl 2-(2-methyl-5-oxopyrrolidin-1-yl)succinate (DMMPS). The MPSA $(0.79 \mathrm{~g}, 3.67 \mathrm{mmol})$ was dissolved in $\mathrm{MeOH}(10 \mathrm{~mL})$ and sulfuric acid $(0.2 \mathrm{~mL}, 0.37 \mathrm{mmol})$ was added. The mixture was heated to reflux for 16 hours. After evaporation of the methanol, the mixture was dissolved in $\mathrm{CH}_{2} \mathrm{Cl}_{2}(30 \mathrm{~mL})$, and washed with a saturated solution of sodium hydrogen carbonate $(20 \mathrm{~mL})$. The organic layer was dried with magnesium sulphate and concentrated under reduced pressure. The resulting oil was subjected to distillation using a Kugelrohr distillation apparatus $\left(100^{\circ} \mathrm{C}, 0.15 \mathrm{mbar}\right)$ to afford the pure diester as a colourless oil (794 $\mathrm{mg}, 89 \%$ yield).

Methyl 3-hydroxy-2-(2-methyl-5-oxopyrrolidin-1-yl)propanoate (MHMPP). The compound was prepared via analogous procedure.

Polymer synthesis. Bulk polymerizations were performed in a $25 \mathrm{~mL}$ onenecked round bottom flask fitted with a bulb to collect the methanol byproduct and adapted on a Büchi Kugelrohr apparatus (method A) or a 50 $\mathrm{mL}$ round bottom flask equipped with an Argon/Vacuum entry, a distillation arm to collect the methanol by-product, a mechanical stirring, and an oil bath $(\operatorname{method} B)$.

Typical procedure for poly[alkylidene 2-(2-methyl-5-oxopyrrolidin-1$\mathrm{yl}$ )succinate] (PAMPS). The flask was charged with DMMPS $(0.50 \mathrm{~g}$, $2.06 \mathrm{mmol}$ ), diol (2.18-2.39 mmol) and catalyst ( $2.06 \mu \mathrm{mol}, 0.1 \mathrm{~mol} \%)$ and then adapted on the reaction apparatus, which was purged three times with argon. The reaction was first performed at $180^{\circ} \mathrm{C}$ under an atmospheric pressure of Argon for 5 hours. During this period, methanol was distilled and collected in the external bulb (method A) or via the distillation arm (method B). The reaction medium was slowly put under vacuum over a period of 1 hour, and then was left at $180{ }^{\circ} \mathrm{C}$ under $0.2 \mathrm{mbar}$ for 8 hours. After cooling down to room temperature, the polymer was collected without further purification.

\section{Acknowledgements}

This work was funded by the FWV ALPO Interreg Grant and the authors thanks the European Regional Development Fund (FEDER) and the University of Lille. Chevreul Institute (FR 2638), Ministère de l'Enseignement Supérieur et de la Recherche, Région Hauts de France are also acknowledged for supporting and funding partially this work. The authors are gratefully acknowledged to Aurélie Malfait for GPC measurements. Dr Julie Meimoun is acknowledged for contribution to DSC and NMR analysis. The UMONS laboratory thanks the FRS-FNRS (Fonds pour le Recherche Scientifique) for financial support for the acquisition of the Waters Synapt G2-Si mass spectrometer.

Keywords: Reductive amination, Biobased polyesters, Levulinic acid • Aspartic acid • Lactam containing polymers • •

[1] a) A. Corma, S. Iborra, A. Velty, Chem. Rev. 2007, 107, 2411; b) J. J. Bozell, G. R. Petersen, Green Chem. 2010, 12, 539; c) A. Gandini, Green Chem. 2011, 13, 1061; d) M. Rose, R. Palkovits, Macromol. Rapid Commun. 2011, 32, 1299.

[2] a) D. Esposito, M. Antonietti, Chem. Soc. Rev. 2015, 44, 5821; b) F H. Isikgor, C. R. Becer, Polym. Chem. 2015, 6, 4497; c) I. Delidovich, P. J. C. Hausoul, L. Deng, R. Pfützenreuter, M. Rose, R. Palkovits Chem. Rev. 2016, 116, 1540; d) L. T. Mika, E. Cséfalvay, Á. Németh Chem. Rev. 2018, 118, 505. e) P. F. H. Harmsen, M. M. Hackmann H. L. Bos, Biofuels Bioprod. Biorefin. 2014, 8, 306.

[3] a) T. Werpy, G. Petersen, Top Value Added Chemicals from Biomass: Volume I - Results of Screening for Potential Candidates from Sugars and Synthesis Gas, 2004.; b) B. Girisuta, L. P. B. M. Janssen, H. J. Heeres, Green Chem. 2006, 8, 701.; c) H. Li, A Riisager, S. Saravanamurugan, A. Pandey, R. S. Sangwan, S. Yang, R Luque, ACS Catal., 2018, 8, 148-187.

[4] a) D. W. Rackemann, W. O. Doherty, Biofuels Bioprod. Biorefin. 2011, 5, 198; b) C. Antonetti, D. Licursi, S. Fulignati, G. Valentini, A M. Raspolli Galletti, Catalysts 2016, 6, 196; c) D. J. Hayes, S. Fitzpatrick, M. H. B. Hayes, J. R. H. Ross, in Biorefineries-Ind. Process. Prod. (Eds.: B. Kamm, P.R. Gruber, M. Kamm), Wiley-VCH Verlag GmbH, Weinheim, Germany, 2005, pp. 139-164.

[5] F. D. Pileidis, M.-M. Titirici, ChemSusChem 2016, 9, 562.

[6] Y.-B. Huang, T. Yang, Y.-T. Lin, Y.-Z. Zhu, L.-C. Li, H. Pan, Green Chem. 2018, 20, 1323.

[7] a) L. Filiciotto, A. M. Balu, J. C. Van der Waal, R. Luque, Catal. Today 2018, 302, 2; b) X. Hu, S. Jiang, L. Wu, S. Wang, C.-Z. Li, Chem. Commun. 2017, 53, 2938; c) S. Yamaguchi, Y. Kawada, H. Yuge, K Tanaka, S. Imamura, Sci. Rep. 2017, 7, 855.

[8] K. Yao, C. Tang, Macromolecules 2013, 46, 1689.

[9] a) L. Yan, Q. Yao, Y. Fu, Green Chem. 2017, 19, 5527; b) Z. Vobecka, C. Wei, K. Tauer, D. Esposito, Polymer 2015, 74, 262.

[10] S. Dutta, L. Wu, M. Mascal, Green Chem. 2015, 17, 2335.

[11] T. Chen, Z. Qin, Y. Qi, T. Deng, X. Ge, J. Wang, X. Hou, Polym. Chem. 2011, 2, 1190.

[12] L. Wu, Y. Zhang, H. Fan, Z. Bu, B.-G. Li, J. Polym. Environ. 2008, 16, 68

[13] a) Y. Zhang, L. Wu, B.-G. Li, J. Appl. Polym. Sci. 2010, 117, 3315; b) A. S. Amarasekara, S. A. Hawkins, Eur. Polym. J. 2011, 47, 2451.

[14] a) A. S. Amarasekara, U. Ha, N. C. Okorie, J. Polym. Sci. Part Polym. Chem. 2018, 56, 955; b) R. D. Ashby, D. K. Y. Solaiman, G. D. Strahan, 
C. Zhu, R. C. Tappel, C. T. Nomura, Bioresour. Technol. 2012, 118, 272; c) J. A. Moore, T. Tannahill, High Perform. Polym. 2001, 13, S305.

[15] P. Mäki- Arvela, B. Holmbom, T. Salmi, D. Y. Murzin, Catal. Rev. 2007, 49, 197.

[16] a) R. D. Clercq, M. Dusselier, B. F. Sels, Green Chem. 2017, 19, 5012; b) P. Dhepe, K. Tomishige, K. C.-W. Wu, ChemCatChem 2017, 9, 2613; c) J. C. Serrano-Ruiz, R. M. West, J. A. Dumesic, Annu. Rev. Chem. Biomol. Eng. 2010, 1, 79; d) P. Marion, B. Bernela, A. Piccirilli, B. Estrine, N. Patouillard, J. Guilbot, F. Jérôme, Green Chem. 2017, 19, 4973; e) S. Shylesh, A. A. Gokhale, C. R. Ho, A. T. Bell, Acc. Chem. Res. 2017, 50, 2589; f) K. Yan, C. Jarvis, J. Gu, Y. Yan, Renew. Sustain. Energy Rev. 2015, 51, 986; g) J. Zhang, S. Wu, B. Li, H. Zhang, ChemCatChem 2012 , 4, 1230; h) U. Omoruyi, S; Page, J. Hallett, P. W. Miller, ChemSusChem 2016, 9, 2037; i) Z. Xue, Q. Liu, J. Wang, T. Mu, Green Chem. 2018, 20 4391; j) J. Sherwood, H. L. Parker, K. Moonen, T. J. Farmer, A. J. Hunt, Green Chem. 2016, 18, 3990. k) Z. Xue, Q. Liu, J. Wang, T. Mu, Green Chem., 2018, 20, 4391.

[17] C. Wu, X. Luo, H. Zhang, X. Liu, G. Ji, Z. Liu, Z. Liu, Green Chem. 2017, $19,3525$.

[18] Y.-B. Huang, J.-J. Dai, X.-J. Deng, Y.-C. Qu, Q.-X. Guo, Y. Fu, ChemSusChem 2011, 4, 1578.

[19] S. Wang, H. Huang, C. Bruneau, C. Fischmeister, ChemSusChem 2017 $10,4150$.

[20] Y. Ogiwara, T. Uchiyama, N. Sakai, Angew. Chem. Int. Ed. 2016, 55, 1864.

[21] X.-L. Du, L. He, S. Zhao, Y.-M. Liu, Y. Cao, H.-Y. He, K.-N. Fan, Angew. Chem. Int. Ed. 2011, 50, 7815.

[22] a) G. Gao, P. Sun, Y. Li, F. Wang, Z. Zhao, Y. Qin, F. Li, ACS Catal. 2017, 7, 4927; b) M. Muzzio, C. Yu, H. Lin, T. Yom, D. A. Boga, Z. Xi, N. Li, Z. Yin, J. Li, J. A. Dunn, S. Sun, Green Chem., 2019, 21, 1895.

[23] a) J. Zhang, B. Xie, L. Wang, X. Yi, C. Wang, G. Wang, Z. Dai, A. Zheng, F.-S. Xiao, ChemCatChem 2017, 9, 2661; b) A. S. Amarasekara, Y. M Lawrence, Tetrahedron Lett. 2018, 59, 1832

[24] J. D. Vidal, M. J. Climent, P. Concepcion, A. Corma, S. Iborra, M. J. Sabater, ACS Catal. 2015, 5, 5812.

[25] a) K. Shimizu, A. S. Touchy, S. M. a. H. Siddiki, A. Bhosale, T. Toyao, Y. Mahara, J. Ohyama, A. Satsuma, ChemCatChem 2017, 10, 789; b) Z. Sun, J. Chen, T. Tu, Green Chem. 2017, 19, 789. c) C. Xie, J. Song, H. Wu, Y. Hu, H. Liu, Z. Zhang, P. Zhang, B. Chen, B. Han, J. Am. Chem. Soc. 2019, 141, 4002.

[26] a) T. Zhang, Y. Ge, X. Wang, J. Chen, X. Huang, Y. Liao, ACS Omega 2017, 2, 3228; b) J. J. Martínez, L. Silva, H. A. Rojas, G. P. Romanelli, L. A. Santos, T. C. Ramalho, M. H. Brijaldo, F. B. Passos, Catal. Today 2017, 296, 118.

[27] Y. Wei, C. Wang, X. Jiang, D. Xue, Z.-T. Liu, J. Xiao, Green Chem. 2014 , 16, 1093.

[28] a) A. Ledoux, L. S. Kuigwa, E. Framery, B. Andrioletti, Green Chem. 2015, 17, 3251; b) C. Wu, H. Zhang, B. Yu, Y. Chen, Z. Ke, S. Guo, Z. Liu, ACS Catal. 2017, 7, 7772; c) F. De Schouwer, L. Claes, N. Claes, S Bals, J. Degrève, D. E. De Vos, Green Chem. 2015, 17, 2263.

[29] a) F. D. Schouwer, S. Adriaansen, L. Claes, D. E. D. Vos, Green Chem. 2017, 19, 4919; b) A. J. J. Straathof, Chem. Rev. 2014, 114, 1871.

[30] E. Scott, F. Peter, J. Sanders, Appl. Microbiol. Biotechnol. 2007, 75, 751.

[31] R. A. Gross, Science 2002, 297, 803.

[32] S. Lambert, M. Wagner, Chem. Soc. Rev. 2017, 46, 5855

[33] a) R. P. Babu, K. O'Connor, R. Seeram, Prog. Biomater. 2013, 2, 8; b) C. Vilela, A. F. Sousa, A. C. Fonseca, A. C. Serra, J. F. J. Coelho, C. S. R. Freire, A. J. D. Silvestre, Polym Chem 2014, 5, 3119; c) K. M. Zia, A. Noreen, M. Zuber, S. Tabasum, M. Mujahid, Int. J. Biol. Macromol. 2016, 82, 1028; d) H. T. H. Nguyen, P. Qi, M. Rostagno, A. Feteha, S. A. Miller, J. Mater. Chem. A 2018, 6, 9298.

[34] P. Qi, H.-L. Chen, H. T. H. Nguyen, C.-C. Lin, S. A. Miller, Green Chem. 2016, $18,4170$.

[35] M. A. Ali, S. Tateyama, Y. Oka, D. Kaneko, M. K. Okajima, T. Kaneko, Macromolecules 2013, 46, 3719.

[36] M. Hartweg, C. R. Becer, Green Chem. 2016, 18, 3272.
[37] Y. Bernhard, L. Pagies, S. Pellegrini, T. Bousquet, A. Favrelle, L. Pelinski, P. Gerbaux, P. Zinck, Green Chem. 2019, 21, 123.

[38] S. Lingier, Y. Spiesschaert, B. Dhanis, S. De Wildeman, F. E. Du Prez, Macromolecules 2017, 50, 5346.

[39] K. Zhang, H. Yang, Z. Qiu, J. Polym. Environ. 2018, 26, 1320.

[40] J. Lu, L. Wu, B.-G. Li, ACS Sustain. Chem. Eng. 2017, 5, 6159.

[41] K. Chrissafis, K. M. Paraskevopoulos, D. N. Bikiaris, Thermochim. Acta 2005, 435, 142

[42] D. N. Bikiaris, G. Z. Papageorgiou, S. A. Papadimitriou, E. Karavas, K. Avgoustakis, AAPS PharmSciTech 2009, 10, 138. 
WILEY-VCH

\section{FULL PAPER}

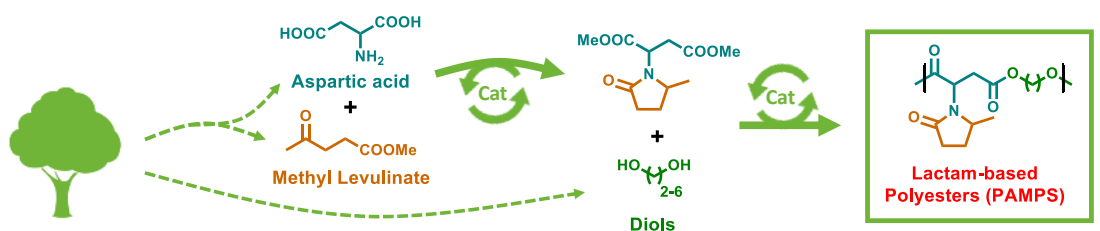

Biobased Polyesters: The renewable building-blocks aspartic and levulinic acids have been combined via a catalytic reductive amination/cyclisation process to yield a novel diester. The latter has been copolymerized with biobased diols to get fully biobased polyesters with a pendant rigid lactam unit.
Yann Bernhard, Sylvain Pellegrini, Till Bousquet, Audrey Favrelle, Lydie Pelinski, Frédéric Cazaux, Valérie Gaucher, Pascal Gerbaux and Philippe Zinck*

\section{Page No. - Page No.}

Reductive Amination/Cyclization of Methyl Levulinate with Aspartic Acid: Towards Renewable Polyesters with a Pendant Lactam Unit 